\title{
Superhydrophobic Hexamethylene Diisocyanate Modified Hydrolyzed Polymers of Intrinsic Microporosity Electrospun Ultrafine Fibrous Membrane for the Adsorption of Organic Compounds and Oil/Water Separation
}

\author{
Bekir Satilmis $*, \dagger, \ddagger$ and Tamer Uyar* ${ }^{* \dagger}$ \\ ${ }^{\dagger}$ National Nanotechnology Research Center, Institute of Materials Science \& Nanotechnology, Bilkent University, Ankara 06800, \\ Turkey \\ ${ }^{\ddagger}$ Faculty of Science and Arts, Department of Chemistry, Ahi Evran University, Kirsehir 40100, Turkey
}

Supporting Information

\begin{abstract}
Polymers of intrinsic microporosity (PIMs) have gained significant research interest because of their successful applications in adsorption and separation. PIM-1 is the first and most studied member of this class because it shows specific interactions with some certain organic species. Chemical modification of PIM-1, which can be achieved by simply hydrolyzing the nitrile groups in the backbone, provides an advantage of tailoring its adsorption and separation performances. In this study, electrospinning of ultrafine fibers from hydrolyzed polymer of intrinsic microporosity (HPIM)

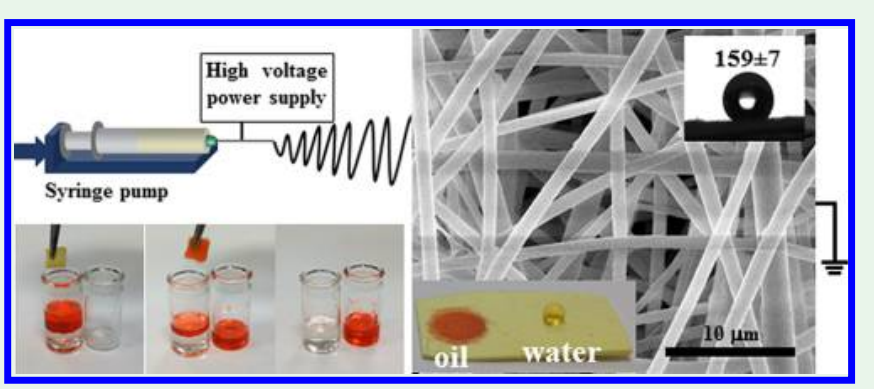
and blends of hexamethylene diisocyanate (HMDI)/HPIM was achieved in several different ratios of HMDI/HPIM ranging from 1:9 to $1: 1(\mathrm{w} / \mathrm{w})$. Bead-free and uniform fibers were obtained in the form of self-standing ultrafine fibrous membranes, which were then thermally treated at $150{ }^{\circ} \mathrm{C}$ to introduce chemical cross-linking between HMDI units and carbonyl groups of HPIM, resulting in HMDI-modified HPIM fibrous membranes (HMDI/HPIM-FMs). The solubility behavior has been altered by an introduced modification that makes membranes insoluble in all common organic solvents. Chemical cross-linking has been confirmed by using a Fourier transform infrared technique showing urethane linkage between HMDI and HPIM, and it was further supported by X-ray photoelectron microscopy and elemental analysis techniques that show a significant increase in the relative ratio of nitrogen in HMDI/HPIM-FMs compared to HPIM-FM. The average fiber diameters of fibrous membranes were found between $1.38 \pm 0.29$ and $0.96 \pm 0.22 \mu \mathrm{m}$ depending on the blend compositions and applied electrospinning parameters. Moreover, the water contact-angle value for HPIM-FM increased with the introduced HMDI modification from $140 \pm 4^{\circ}$ to 159 $\pm 7^{\circ}$, changing the nature of the membrane from hydrophobic to superhydrophobic. Consequently, HMDI/HPIM-FMs were successfully employed in oil/water separation due to the superhydrophobicity. In addition, the adsorption properties of HPIMFM and HMDI/HPIM-FMs were explored for common organic solvents. While both HPIM-FM and HMDI/HPIM-FMs show promising results, the structural stability of HMDI/HPIM-FMs in liquids was found to be more stable and reusable with respect to HPIM-FM. Hence, HMDI/HPIM-FMs are more favorable for organic adsorption and separation purposes from an aqueous system.
\end{abstract}

KEYWORDS: polymers of intrinsic microporosity (PIM-1), electrospinning, superhydrophobic, organic removal, oil/water separation

\section{INTRODUCTION}

The issue of water pollution has gained tremendous attention in recent years because it has become a worldwide challenge. Water pollution is mainly caused by industrial actions and oil spill accidents that lead to serious environmental damage. ${ }^{1,2}$ Therefore, oil spill cleanup is an urgent task, and the need for producing cost-effective and environmentally friendly methods and materials is an ongoing demand. ${ }^{3-6}$ Several methods have been introduced for oil spill cleanup including in situ burning of oil on water, ${ }^{7}$ chemical degradation, ${ }^{8}$ mechanical extraction, ${ }^{9}$ and centrifugation. Each has its own limitations and most have low separation efficiency and high operation cost and require complex equipment. Among these cleanup strategies, the most promising technique is considered to be the use of sorbent materials that can selectively separate oil/water mixtures. ${ }^{10}$ One of the most required properties for ideal sorbents is maintaining special wettable surfaces, such as superhydrophobic/superoleophilic surfaces. ${ }^{11-13}$ Superhydrophobic surfaces display water contact angles of greater than $150^{\circ}$ and can be prepared by controlling the chemical composition and topological

Received: January 20, 2018

Accepted: March 29, 2018

Published: March 29, 2018 
structures. ${ }^{12}$ Until now, several methods have been employed to obtain superhydrophobic surfaces such as colloidal assembly, ${ }^{14}$ layer-by-layer deposition, ${ }^{15}$ chemical deposition, ${ }^{16}$ template-based techniques, ${ }^{17}$ and electrospinning. ${ }^{18,19}$ Electrospinning is one of the most peaked techniques for the fabrication of superhydrophobic polymeric or composite nanofibers. ${ }^{18-20}$ Thus, a number of electrospun materials have been reported for oil/water separation. ${ }^{19,21,22}$

In the past few years, great emphasis has been put on the research of the synthesis and applications of microporous materials that were obtained from purely organic components because of their outstanding performances in adsorption and separation. ${ }^{23}$ Polymers of intrinsic microporosity (PIMs) have been developed based on this approach. PIMs possess rigid and contorted structures that limit the packing efficiency. Therefore, they have high specific surface area and high chemical and thermal stabilities, which make them suitable for several applications. $^{24-29}$ PIM-1 is the first and most studied member of the PIM family because it can be synthesized by using

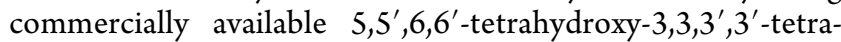
methyl-1,1'-spirobisindane and tetrafluoroterephthalonitrile monomers. PIM-1 is soluble in common organic solvents such as chloroform, tetrahydrofuran, and dichloromethane, and thus it can be prepared in the form of powder, membrane, and fiber, showing excellent performance in adsorption and separation applications. ${ }^{30-32}$ Recently, electrospun PIM-1 was introduced, $^{33}$ and it has been utilized successfully for adsorption and separation purposes. ${ }^{31,34}$ PIM-1 possesses nitrile units in the backbone, which enables possible postmodification reactions to alter the properties of PIM-1 for the desired applications. ${ }^{30}$ Therefore, some efforts have been devoted to the modification of PIM-1. Hydrolysis is the most studied modification among all of them because of the simple reaction conditions. ${ }^{35-41}$ From this standpoint, Zhang et al. ${ }^{42}$ studied the post-treatment of an electrospun PIM-1 fiber with a base to obtain a hydrolyzed PIM-1 (HPIM) fiber. The study revealed that the dye removal ability of electrospun PIM-1 toward cationic dyes in aqueous media has been improved by hydrolysis. However, the hydrolysis procedure has caused severe damage to the mechanical and structural integrity of fibers. Recently, we introduced a new strategy to fabricate selfstanding, electrospun HPIM ultrafine fibrous membranes as a molecular filter to remove methylene blue from an aqueous solution, showing a high removal efficiency. ${ }^{43}$

In this study, we reported a facile approach to the further modification of HPIM with 1,6-hexamethylene diisocyanate (HMDI) in order to obtain superhydrophobic ultrafine fibers using an electrospinning technique. Chemically cross-linked, self-standing, HMDI-modified HPIM fibrous membranes (HMDI/HPIM-FMs) showed improved hydrophobicity with increased water contact angle. After modification, HMDI/ HPIM-FMs became insoluble, which enhanced the structural stability of membranes against several organic compounds. Thanks to their superhydrophobicity and insolubility, HMDI/ HPIM-FMs were successfully employed in oil/water separation as well as organic removal applications.

\section{EXPERIMENTAL SECTION}

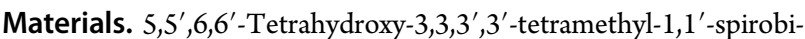
sindane (98\%, Alfa Aesar) and tetrafluoroterephthalonitrile (98\%, Aldrich) were recrystallized as reported previously. ${ }^{35}$ Anhydrous potassium carbonate $\left(99.0 \%\right.$, Fisher) was dried in an oven at $110{ }^{\circ} \mathrm{C}$ overnight. 1,6-Hexamethylene diisocyanate (HMDI; >98\%, Aldrich), dimethylformamide (DMF), ethanol (EtOH), dimethylacetamide, methanol $(\mathrm{MeOH})$, toluene, sodium hydroxide, tetrahydrofuran (THF), dimethyl sulfoxide (DMSO), dichloromethane (DCM), hexane, chloroform $\left(\mathrm{CHCl}_{3}\right)$, sunflower oil (Yudum, obtained from a local shop), pump oil (Edwards 19, ultragrade vacuum oil), and silicone oil were used as received. The synthesis and hydrolysis of PIM-1 was conducted as reported previously. ${ }^{43}$

Electrospinning. For electrospinning of HPIM, HPIM powder $(0.35 \mathrm{~g})$ was dissolved in DMF $(0.5 \mathrm{~mL})$ to obtain $70 \%(\mathrm{w} / \mathrm{v})$ polymer concentration, and the HPIM solution was stirred at room temperature for $4 \mathrm{~h}$ and then degassed for $15 \mathrm{~min}$. After that, the solution was loaded into a $1 \mathrm{~mL}$ syringe fitted with a blunt needle $(0.5$ $\mathrm{mm}$ diameter) and placed horizontally on a syringe pump (KDS101, $\mathrm{KD}$ Scientific). Microfibers were collected on aluminum foil and then ground by a metal collector. Electrospinning was performed using a commercial spinner (Nanoweb 350, Mavi Teknik, Mersin/Turkey). The applied parameters were as follows: flow rate, $0.5 \mathrm{~mL} \mathrm{~h}^{-1}$; voltage, $11 \mathrm{kV}$; distance, $16 \mathrm{~cm}$. Then the collected fibers were removed from the aluminum surface by tweezers. Finally, the HPIM fiber was dried in an oven at $150{ }^{\circ} \mathrm{C}$ for $2 \mathrm{~h}$. HMDI/HPIM blend solutions were prepared in several different ratios ranging from 1:9 (w/w) (H10) to $1: 1(\mathrm{w} / \mathrm{w})(\mathrm{H} 50)$ while maintaining the same amount of HPIM [0.35 $\mathrm{g}$ in $0.5 \mathrm{~mL}$ of DMF; $70 \%(\mathrm{w} / \mathrm{v})$ ]. Similarly, a HPIM solution was first prepared, and predetermined amounts of HMDIs were added to this and stirred at room temperature for an additional $1 \mathrm{~h}$. The solution was degassed for $15 \mathrm{~min}$ prior to the electrospinning process. The electrospinning parameters of blend mixtures were identical with those of HPIM, and cross-linking of the electrospun HMDI/HPIM-FMs was carried out at $150{ }^{\circ} \mathrm{C}$ for $2 \mathrm{~h}$ in an oven.

Additionally, $\mathrm{H} 50$ has been prepared in the dense membrane (film) form using the same HPIM/HMDI compositions in $2 \mathrm{~mL}$ of DMF. The solution was placed in a glass Petri dish and heated to $60{ }^{\circ} \mathrm{C}$ for 3 h. Then it was dried at $150{ }^{\circ} \mathrm{C}$ in an oven for $2 \mathrm{~h}$.

Methods. A Bruker Alpha P spectrometer was used to collect attenuated total reflectance infrared (ATR-IR) spectra of samples that were scanned 64 times at a resolution of $4 \mathrm{~cm}^{-1}$. ${ }^{1} \mathrm{H}$ NMR spectra of the samples were recorded using a Bruker DPX-400 $\mathrm{MHz}$ spectrometer. Samples were dissolved in DMSO- $d_{6}$. X-ray photoelectron spectroscopy (XPS) spectra were obtained by a flood gun charge neutralizer system equipped with a monochromated $\mathrm{Al} \mathrm{K} \alpha \mathrm{X}$ ray source. Elemental analysis was carried out using a Thermo Scientific Flash 2000 series CHNS-O analyzer. 2,5-[Bis(5-tert-butyl-2benzooxazol-2-yl)]thiophene and vanadium pentoxide were used as a standard and a catalyst, respectively. The morphology of the samples was studied by scanning electron microscopy (SEM; FEI Quanta 200 FEG). The samples were coated with $5 \mathrm{~nm}$ of gold/palladium prior to imaging. The average fiber diameters were determined using ImageJ software. Thermogravimetric analysis (TGA; Q500, TA Instruments) was utilized to explore the thermal resistance of samples that were heated up to $600{ }^{\circ} \mathrm{C}$ at a heating rate of $20^{\circ} \mathrm{C} \min ^{-1}$ under $\mathrm{N}_{2}$. The thermal properties of the samples were also investigated using differential scanning calorimetry (DSC; Q2000, TA Instruments). The samples were heated to $500{ }^{\circ} \mathrm{C}$ at $20{ }^{\circ} \mathrm{C} \min ^{-1}$ under a $\mathrm{N}_{2}$ atmosphere. For DSC measurements, the samples were equilibrated at $0{ }^{\circ} \mathrm{C}$ and then heated to $500{ }^{\circ} \mathrm{C}$ at $20{ }^{\circ} \mathrm{C} \mathrm{min}^{-1}$ under a $\mathrm{N}_{2}$ atmosphere. Water contact-angle data of the samples were obtained by a Dataphysics water contact-angle system (OCA) using deionized water $(0.4 \mu \mathrm{L})$, which was automatically dropped onto the nanofibrous mats, and a Laplace-Young fitting was applied to the measurements. The measurements were repeated 10 times at different positions for an average value. The mechanical properties of the samples were examined using dynamic mechanical analysis (DMA; Q800, TA Instruments). The thicknesses of the samples were measured using a Fowler ProMax digital caliper. Rectangular-shaped samples $(8 \times 6 \times$ $0.02 \mathrm{~mm}$ ) were employed to obtain stress-strain curves in controlled force mode with a $0.05 \mathrm{~N} \mathrm{~min}^{-1}$ force ramp rate by three different samples at room temperature. Young's modulus was obtained from the linear region of the curves. Similarly, the storage modulus was tested for rectangular-shaped samples $(15 \times 6 \times 0.02 \mathrm{~mm})$ in multifrequency mode with an amplitude value of $5 \mu \mathrm{m}$. Samples were heated to 200 
Table 1. Samples Codes, Compositions, Elemental Analysis Data, Average Fiber Diameters $(\mu \mathrm{m})$, Water Contact Angles $(\theta)$, and Atomic Percentages of HPIM-FM and Cross-Linked HMDI/HPIM-FMs

\begin{tabular}{|c|c|c|c|c|c|c|c|c|c|}
\hline \multirow[b]{2}{*}{ sample code } & \multirow[b]{2}{*}{ HMDI/HPIM (w/w) } & \multicolumn{3}{|c|}{ elemental analysis (wt \%) } & \multirow[b]{2}{*}{ average fiber diameter $(\mu \mathrm{m})$} & \multirow[b]{2}{*}{ water contact angle $(\theta)$} & \multicolumn{3}{|c|}{ atomic \% (XPS) } \\
\hline & & $\mathrm{C}$ & $\mathrm{N}$ & $\mathrm{H}$ & & & $\mathrm{C}$ & $\mathrm{N}$ & $\mathrm{O}$ \\
\hline HPIM & $0: 10$ & 64.9 & 5.6 & 5.2 & $1.38 \pm 0.29$ & $140 \pm 4$ & 89.6 & 3.6 & 6.7 \\
\hline $\mathrm{H} 10$ & $1: 9$ & 65.4 & 6.9 & 5.5 & $1.36 \pm 0.64$ & $144 \pm 2$ & 88.5 & 4.3 & 7.3 \\
\hline $\mathrm{H} 20$ & $1: 4$ & 65.2 & 7.7 & 5.8 & $1.34 \pm 0.49$ & $150 \pm 4$ & 88.5 & 4.6 & 6.9 \\
\hline $\mathrm{H} 33$ & $1: 2$ & 64.8 & 8.7 & 6 & $1.04 \pm 0.24$ & $153 \pm 4$ & 87.3 & 5.8 & 6.9 \\
\hline $\mathrm{H} 50$ & $1: 1$ & 63.5 & 10.1 & 6.4 & $0.96 \pm 0.22$ & $159 \pm 7$ & 88.9 & 6.0 & 5.1 \\
\hline
\end{tabular}

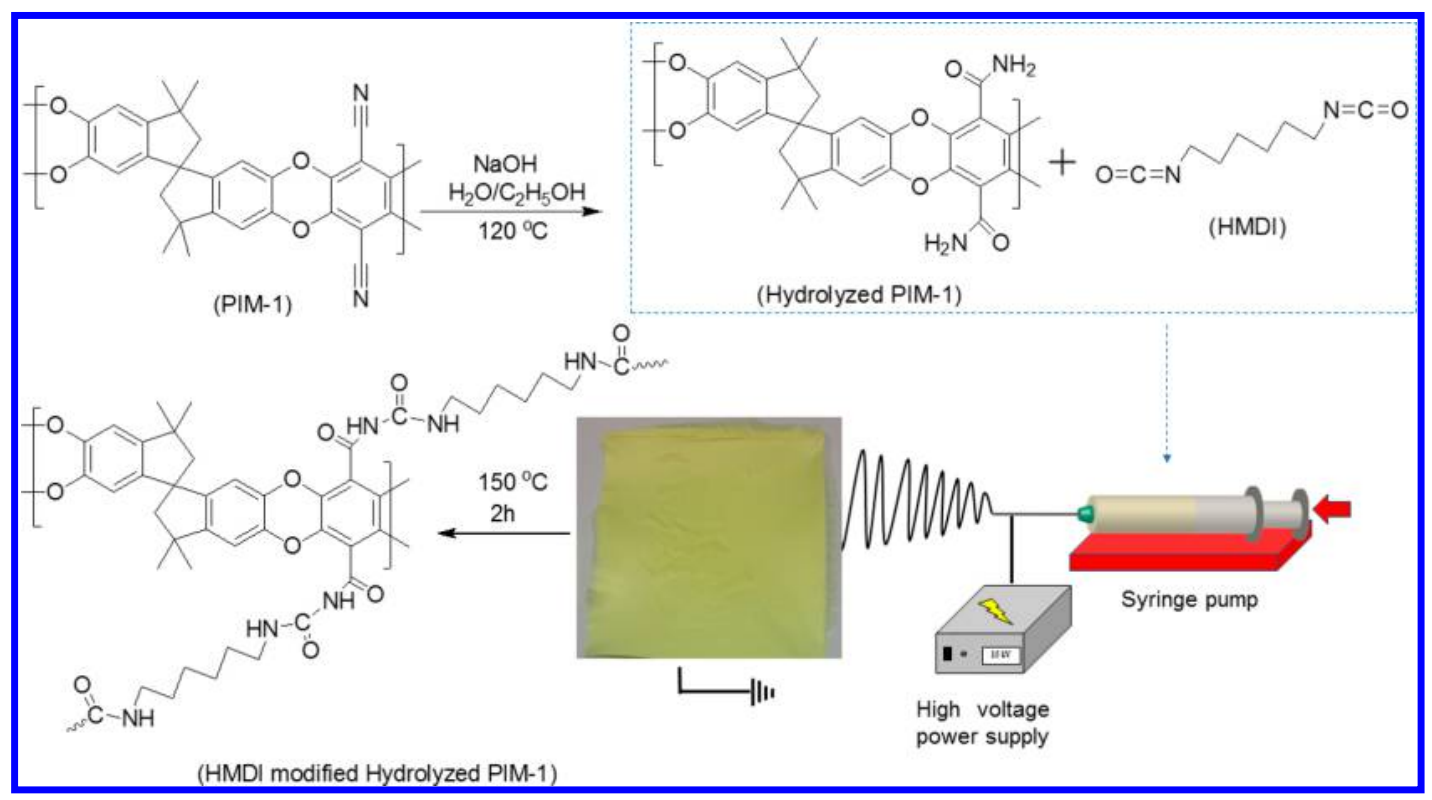

Figure 1. Estimated structure, synthesis path, and electrospinning process of HMDI/HPIM.

${ }^{\circ} \mathrm{C}$ at $3{ }^{\circ} \mathrm{C} \mathrm{min}^{-1}$. Nitrogen adsorption/desorption isotherms of the samples were obtained at $-196{ }^{\circ} \mathrm{C}$ using an Autosorb iQ gas sorption analyzer. The samples $(\sim 0.05 \mathrm{~g})$ were degassed under high vacuum at $120{ }^{\circ} \mathrm{C}$ for $16 \mathrm{~h}$ before analysis. A multipoint analysis method was applied to calculate the Brunauer-Emmett-Teller (BET) surface areas.

Adsorption of Organic Compounds and Oils. For performance evaluation, fibrous membranes $(1 \times 1 \mathrm{~cm})$ were immersed in organic liquids for an hour and then taken out for weight measurements. The membranes' weights before and after adsorption were recorded to estimate the adsorption capacity. The weight measurements were performed immediately after the membranes were taken out of the liquid to avoid any evaporation effect. The percent weight gain was calculated based on eq 1

$$
\% \text { weight gain }=\frac{m_{1}-m_{0}}{m_{0}} \times 100
$$

where $m_{0}$ and $m_{1}$ are the weights of the fibrous membranes before and after adsorption, respectively. The regeneration and adsorption/ desorption performances of HMDI/HPIM-FMs were tested by H50 $(2 \times 1 \mathrm{~cm}, 15 \mathrm{mg})$ for 10 cycles using pump oil. After the weight measurements, the membranes were washed with hexane and immediately used for the next adsorption. Comparisons were made by film form of the same polymer.

Separation Experiments. For the oil/water separation experiments, $3 \mathrm{~mL}$ each of pump oil and water were mixed and the oil was colored with Sudan III. Free-standing fibrous membranes $(\sim 15 \mathrm{mg})$ with dimensions of $2 \times 1 \mathrm{~cm}$ were immersed in the mixture to separate the oil from the mixture. The adsorbed oil was transferred to another sample vial. Following that, the membranes were immersed in hexane, and they were gently rinsed with the help of tweezers to remove adsorbed oil from the fibrous membrane surface. An oil/water separation experiment was performed using sample $\mathrm{H} 50$ for 5 continuous cycles.

\section{RESULTS AND DISCUSSION}

Structural Characterization of PIM-1 and HPIM. The synthesis and characterization of PIM-1 and HPIM are now well-known; thus, detailed structural characterization and purity of PIM-1 and HPIM were performed based on previous studies. ${ }^{43}$ The ATR-IR and ${ }^{1} \mathrm{H}$ NMR spectra and TGA curves of PIM-1 and HPIM powders are provided in Figure S1.

Electrospinning HPIM and HMDI/HPIM-FMs. The properties and applications of powder and film form of PIM1 have been reported in the literature..$^{30,44,45}$ The electrospinning of fibers from PIM-1 is a fairly new concept compared to those of powder and film form. ${ }^{31,33}$ Recently, we reported the electrospinning of HPIMs and their optimized parameters to obtain uniform bead-free fibers along with their dye adsorption abilities based on the degree of hydrolysis. ${ }^{43}$ In the present study, initially we performed the electrospinning of fully hydrolyzed PIM-1 (HPIM) ultrafine fibers in DMF, which is similar to a previous report. ${ }^{43}$ Subsequently, mixtures of HMDI/HPIM were prepared in DMF in different compositions (Table 1) for the electrospinning of fibrous membranes (HMDI/HPIM-FMs). Bead-free and uniform ultrafine fibers were obtained under the same electrospinning parameters as pristine HPIM fibers. Consequently, HMDI/HPIM-FMs were heated at $150{ }^{\circ} \mathrm{C}$ for $2 \mathrm{~h}$ to dry the membranes and to catalyze the cross-linking reaction. The optimization process of membrane production is explained in detail in Figures S2- 


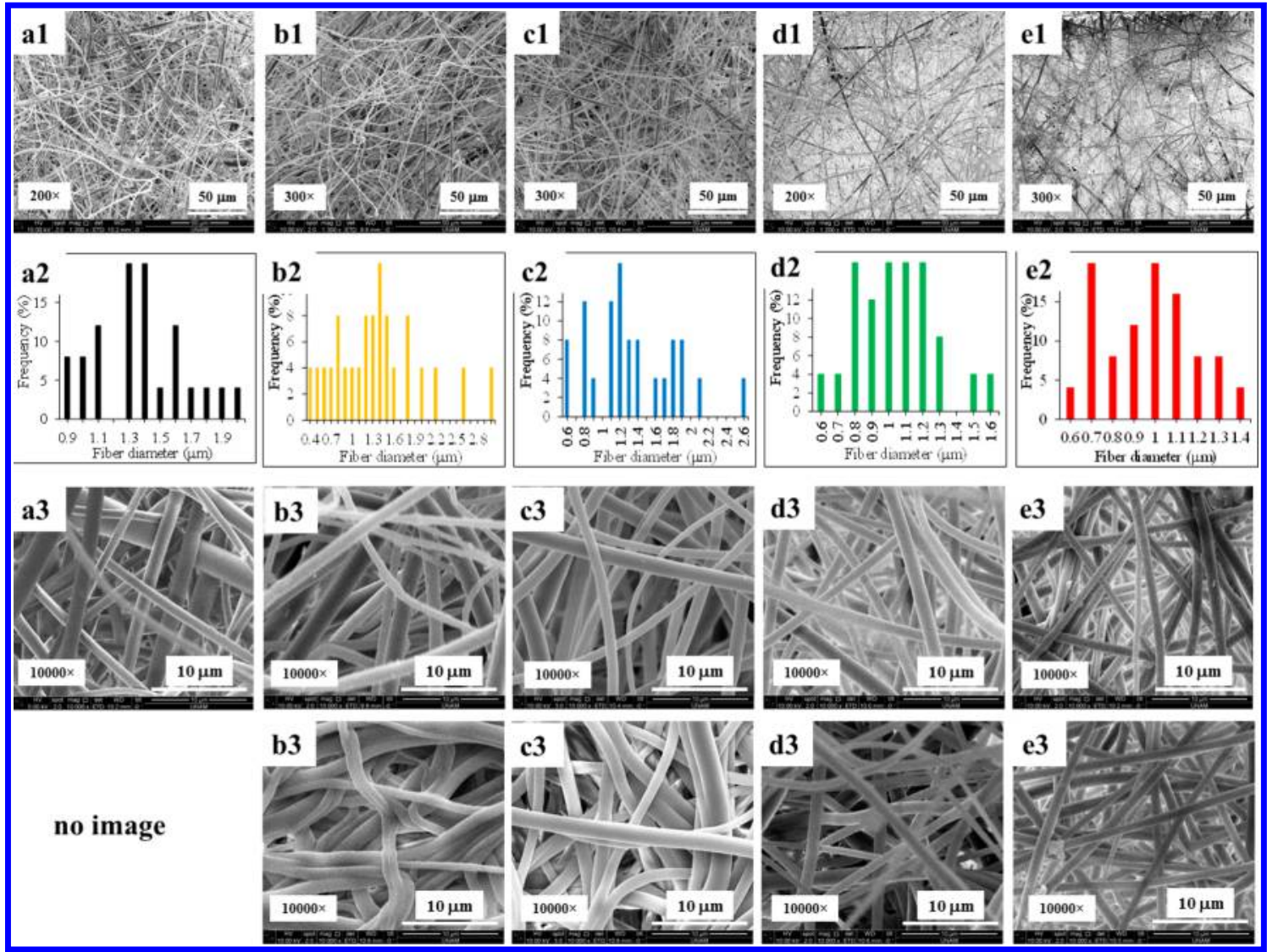

Figure 2. SEM images of HPIM-FM and cross-linked HMDI/HPIM-FMs (1) at 200-300× magnification, (2) average fiber diameter distributions, (3) before DMF treatment at $10000 \times$ magnification, and (4) after DMF treatment for $24 \mathrm{~h}$ at 10000× magnification: (a) HPIM; (b) H10; (c) H20; (d) H33; (e) H5O.

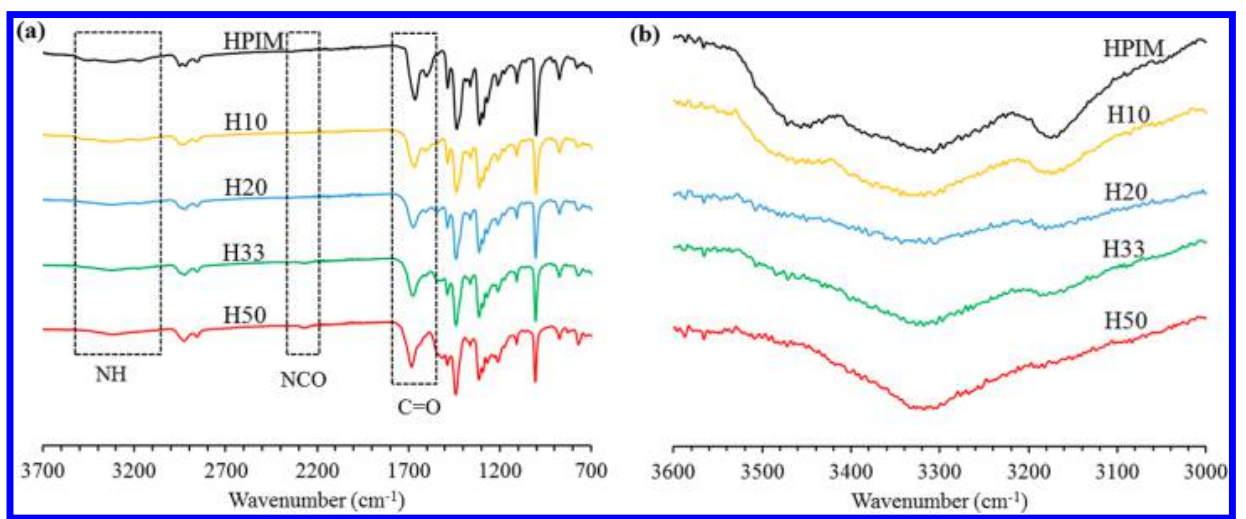

Figure 3. FT-IR spectra of (a) HPIM-FM and HMDI/HPIMs-FMs and (b) the magnified -NH regions of the corresponding samples.

S4. The electrospinning process, reaction pathway, and estimated structures of HMDI/HPIM-FMs are displayed in Figure 1.

SEM images and average fiber diameter distributions of HPIM-FM and cross-linked HMDI/HPIM-FMs are displayed in Figure 2. All samples show bead-free and relatively uniform fibrous morphology. Furthermore, the average fiber diameters were found to be between $1.38 \pm 0.29$ and $0.96 \pm 0.22 \mu \mathrm{m}$ (Table 1), depending on the amount of HMDI added to the HPIM solution for electrospinning. The reduction in the average fiber diameter was explained by the miscibility of HMDI and DMF because they can mix easily without precipitating HPIM. HMDI, which is added to the HPIM solution, acts as a solvent along with DMF. Owing to the increased volume of the solvent, the concentration of HPIM decreased, resulting in a smaller fiber diameter. The solubility of HPIM-FM changed after cross-linking with HMDI, and thus the HMDI/HPIM-FMs became insoluble in common organic solvents (THF, $\mathrm{CHCl}_{3}$, hexane, diethyl ether, DCM, acetonitrile, $\mathrm{MeOH}, \mathrm{EtOH}, 2$-propanol, DMSO, DMF, and $\mathrm{N}$-methyl-2-pyrrolidone), which indicates more stable materials against solvents. The samples were soaked in an electrospinning solvent (DMF) overnight to examine the success of the crosslinking reaction between HPIM and HMDI, and SEM images were obtained before and after treatment, as shown in Figure 2. While HPIM fibers were immediately dissolved, samples with less HMDI content ( $\mathrm{H} 10$ and $\mathrm{H} 20)$ showed slight swelling behavior in DMF. However, samples with more HMDI content 
(H33 and H50) exhibited no swelling behavior in DMF, indicating that the structure stability of the fibers was improved by increasing the amount of HMDI used in the preparation of HMDI/HPIM-FMs.

Structural Characterization of HMDI/HPIMs. Structural characterization of HMDI/HPIM-FMs was conducted using both Fourier transform infrared (FT-IR) and XPS measurements, and the effect of the HMDI content on the chemical structure was studied by altering the amount of HMDI in the fibrous membrane. The FT-IR spectra of HPIM-FM and HMDI/HPIM-FMs are depicted in Figure 3a. It can be seen that HPIM shows several $-\mathrm{NH}$ peaks in the region $3100-3500$ $\mathrm{cm}^{-1}$, which gradually turns a single $-\mathrm{NH}$ peak because of the formation of a urea structure. ${ }^{46,47}$ The expended spectra of this region are also shown in Figure $3 \mathrm{~b}$. In addition, the carbonyl peaks of amides 1 and $2\left(1600\right.$ and $\left.1660 \mathrm{~cm}^{-1}\right)$ also disappear after chemical cross-linking and turn into a single peak while shifting slightly to $1680 \mathrm{~cm}^{-1}$. Moreover, the signals around $2260 \mathrm{~cm}^{-1}$ indicate the presence of NCO functionality. The presence of this peak can be explained by the bifunctional structure of HMDI. It can be observed to be due to either the unreacted side of HMDI or a slight excess of HMDI usage. ${ }^{48,49}$

The XPS spectra of the corresponding samples are also displayed in Figure 4, and a clear intensity increased can be

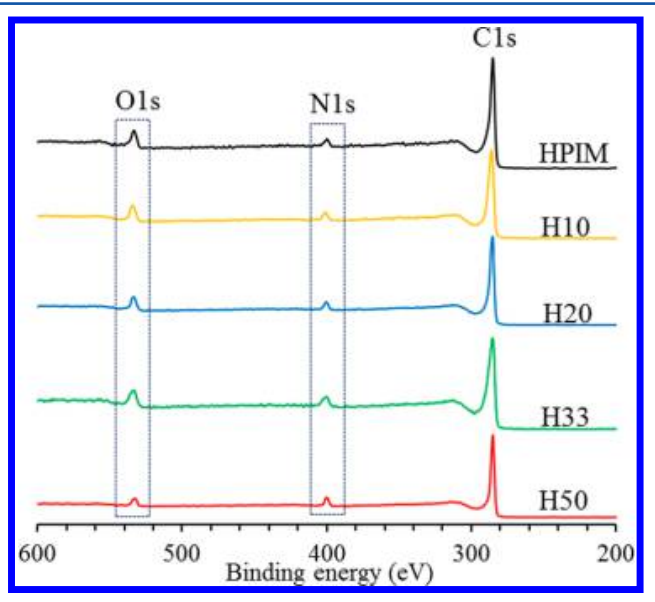

Figure 4. XPS spectra of HPIM-FM and HMDI/HPIMs-FMs.

seen by integration of the $\mathrm{N} / \mathrm{O}$ ratio, which increases from 0.54 to 1.19 by HMDI modification of HPIM. The nitrogen contents of HMDI/HPIM-FMs are increased by chemical cross-linking compared to HPIM-FM. This was also supported by elemental analysis of electrospun HMDI/HPIM-FMs, which is displayed in Table 1. While the carbon content does not change significantly, the nitrogen content increases proportionally from 5.6 to $10.1 \%$, which highlights the addition of HMDI units to the HPIM structure.

The thermal properties of HMDI/HPIM-FMs were investigated using TGA and DSC techniques. Clear differences in the thermal stability were observed, as displayed in Figure 5a. The HPIM fiber shows a small weight loss $(\sim 3 \%)$ around 150 ${ }^{\circ} \mathrm{C}$, which may be due to either the small amount of DMF trapped in the fibers because its powder form does not show this weight loss (Figure S1c) or decomposition of the carboxylate salt present in HPIM. Then the polymer starts to degrade from 240 to $540{ }^{\circ} \mathrm{C}$, which is due to amide functional group and polymer backbone degradation, respectively. ${ }^{35}$ HMDI/HPIM-FMs show two significant degradation steps based on the amount of the HMDI content. The first degradation occurs between 240 and $330{ }^{\circ} \mathrm{C}$ because of decomposition of the urethane groups. ${ }^{50}$ The second one happens because of degradation of the HPIM backbone. Similar degradation behaviors are also observed in the DSC measurements, as presented in Figure $5 b$.

Furthermore, the mechanical behaviors of HMDI/HPIMFMs were also investigated by the DMA technique. The mechanical strengths of HMDI/HPIM-FMs were found to be higher than that of pristine HPIM-FM. The stress-strain curves of selected samples are displayed in Figure 6a. Young's moduli of the samples were found to be $5 \pm 0.4,25 \pm 2$, and $110 \pm 23 \mathrm{MPa}$ for HPIM, H20, and H50 respectively. Crosslinking usually increases the storage modulus of the polymer because of a reduction in the chain mobility. ${ }^{51}$ The mechanical strength of HPIM improved after cross-linking with HMDI, and storage moduli of the selected samples are presented as a function of the temperature in Figure $6 \mathrm{~b}$. An increase in the amount of the HMDI content of the membrane increased the storage moduli of the samples, which were found to be $0.4,3.2$, and 14.3 MPa for HPIM, H20, and H50, respectively, at 200 ${ }^{\circ} \mathrm{C}$. Visual representations of the flexibilities of HPIM-FM and HMDI/HPIM-FMs are provided as supporting video S1 (HPIM) and supporting video S2 (H50).

In this study, we examined the hydrophobicity of HPIM-FM and, unlike its film form, ${ }^{35}$ which has a water contact angle of

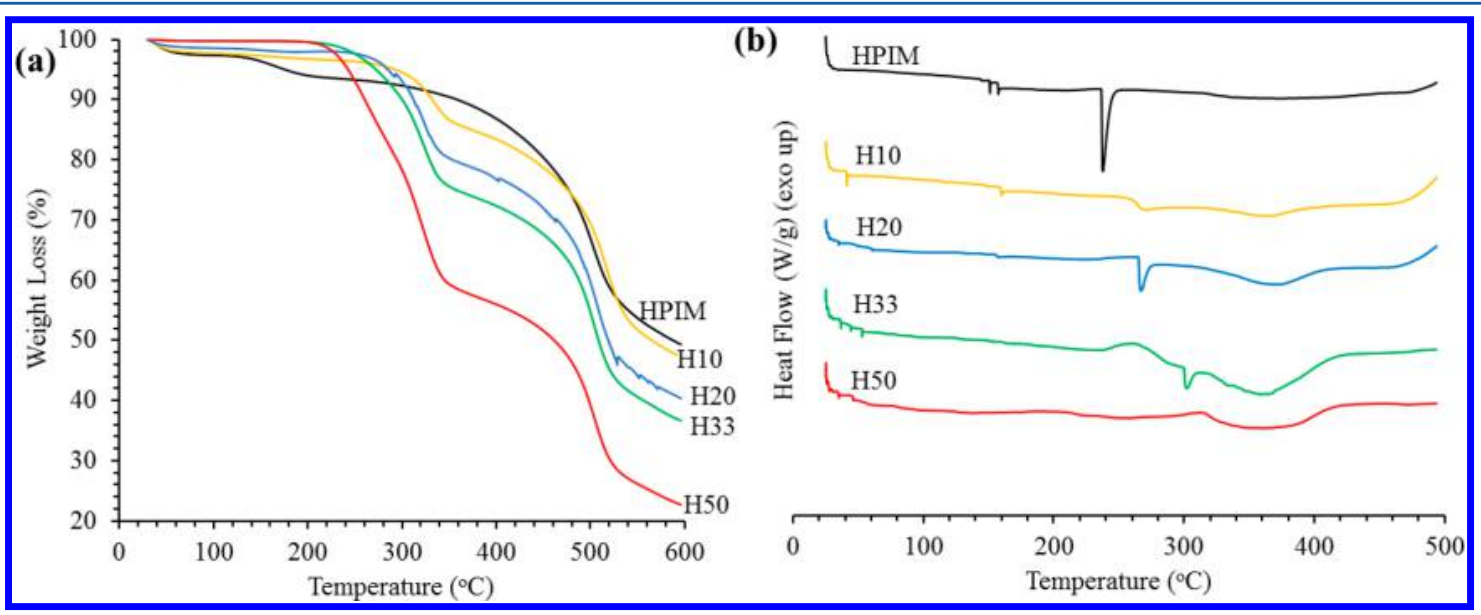

Figure 5. (a) TGA curves of HPIM-FM and HMDI/HPIMs-FMs and (b) DSC curves of the corresponding samples. 


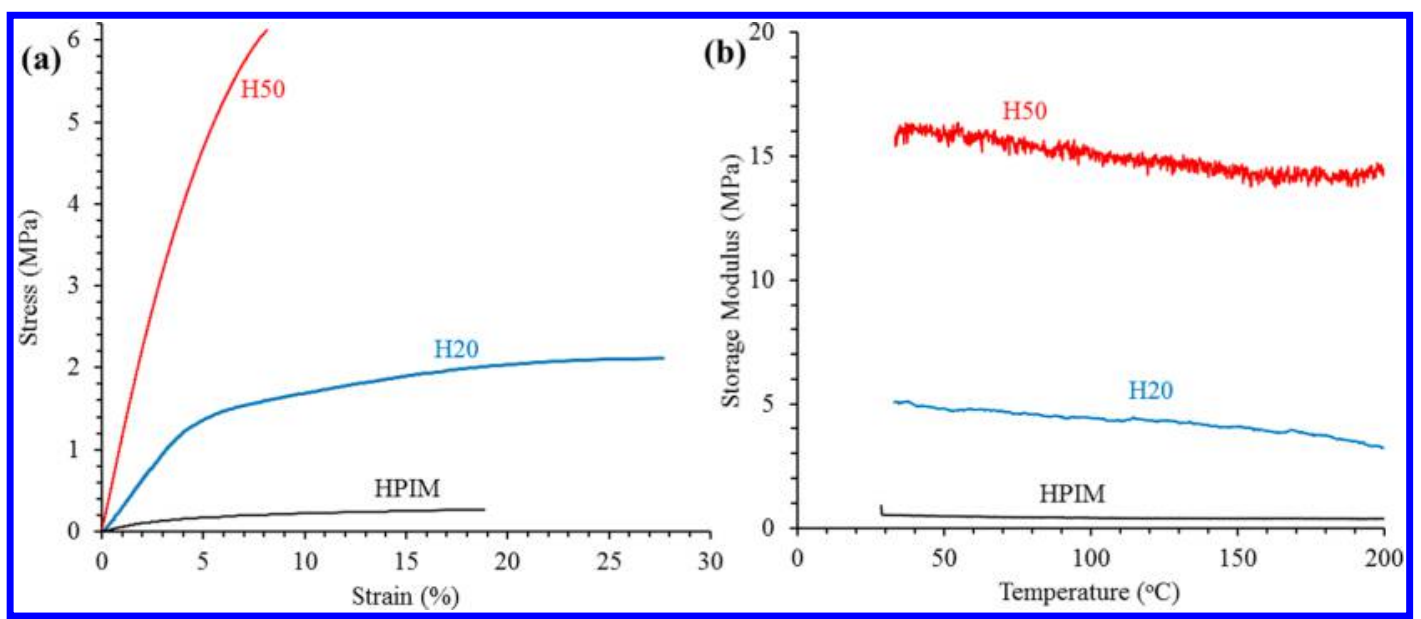

Figure 6. Representative (a) stress-strain curves and (b) storage modulus-temperature graphs of HPIM-FM and HMDI/HPIM-FMs.

about $60^{\circ}$, the water contact angle of HPIM-FM was found to be $140 \pm 4^{\circ}$ (Table 1 and Figure $7 \mathrm{a}$ ). The result, in general, is

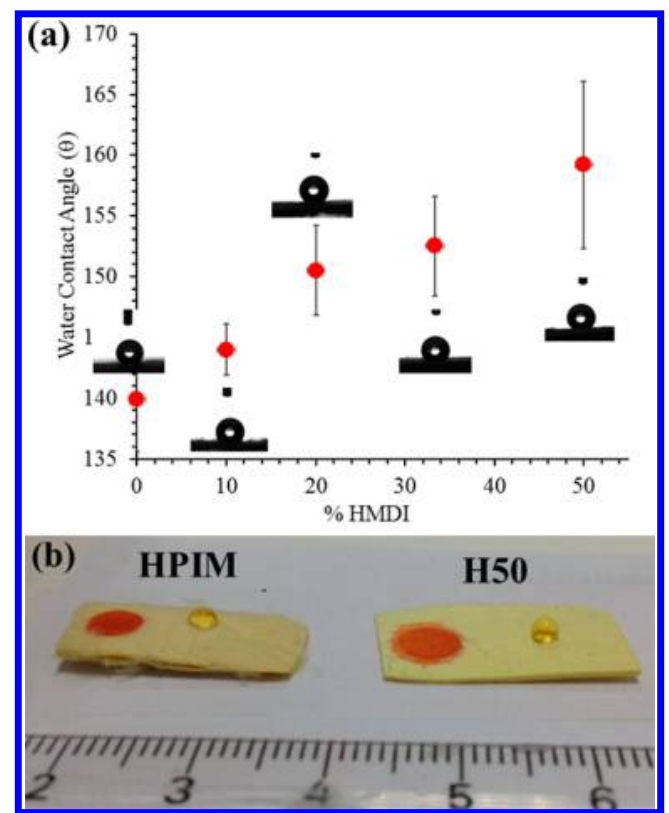

Figure 7. (a) Water contact angle versus \% HMDI for HMDI/HPIMFMs and (b) a digital image of pump oil (red) and water droplets (yellow) on HPIM and H50. The oil was colored by Sudan III dye, and water was colored by orange II dye.

in accordance with the previous studies. Mostly, the value of the contact angle depends on the surface roughness, and it increases with an improved surface roughness. Therefore, fibrous membranes are more hydrophobic than the films. ${ }^{52,53}$ In addition, the effect of cross-linking HPIM with HMDI on the hydrophobicity was also studied, and it was found that membranes became superhydrophobic depending on the amount of HMDI unit integrated in the polymer. As shown in Figure 7a, the water contact angle of H50 (50\% HMDI) reached up to $159 \pm 7^{\circ}$, indicating a superhydrophobic surface, which makes it a great candidate for oil/water separation. Figure $7 \mathrm{~b}$ displays digital images of the oil and water droplets on the surface of HPIM and HMDI/HPIM-FM (H50). A drop of oil could be immediately adsorbed by both fibrous membranes, but water remains as a droplet on the surfaces.
The prepared HMDI/HPIM-FMs have hydrophobic surfaces along with $3 \mathrm{D}$ interconnected pore structures. Hence, it was expected to be a good candidate for the adsorption of organic compounds. Several different oils (silicone oil, pump oil, and sunflower oil) and organic solvents $\left(\mathrm{MeOH}, \mathrm{CHCl}_{3}, \mathrm{DCM}\right.$, hexane, toluene, DMF, and DMSO) were tested to investigate the adsorption capacities of HPIM-FM and HMDI/HPIM-FMs for organic compounds. As shown in Figure S5, both HPIMFM and HMDI/HPIM-FM (H50) were soaked in organic liquids for $1 \mathrm{~h}$. While HPIM is soluble in DMSO and DMF, $\mathrm{H} 50$ is insoluble in any common organic solvent that we tested. The weight-based adsorption capacities of HPIM and H50 fibrous membranes are given in Figure 8a. Also, data are presented in Table S1. While both fibrous membranes show high adsorption capacities against organic compounds, HPIMFM shows a greater adsorption capacity, which is possibly due to the fluffy characteristic of the sample. Liquids can penetrate the HPIM structure more easily than they can H50, that has a more film-like structure, as provided in supporting video $\mathrm{S} 1$ (HPIM) and supporting video S2 (H50). Even though the adsorption capacity of $\mathrm{H} 50$ is lower than that of HPIM, H50 is able to adsorb DMSO and DMF better than HPIM-FM thanks to its insolubility. The maximum weight gain can reach up to $3400 \%$ for HPIM-FM and $2000 \%$ for $\mathrm{H} 50$ for $\mathrm{CHCl}_{3}$ adsorption. Similarly, silicone oil adsorption can reach over $2000 \%$ for both fibrous membranes. Nevertheless, the insolubility in the organic solvents and the structural stability of H50 make it a better candidate for adsorption studies because the reusability is as important as the capacity for an efficient adsorbent. It is possible to reuse $\mathrm{H} 50$ by simply using hexane, but HPIM-FM can lose its physical properties in oils or after removal of oil with hexane, as shown in Figure S6. Therefore, the performance of $\mathrm{H} 50$ in adsorption was investigated for pump oil adsorption for 10 cycles. After 10 adsorption/desorption cycles, H50 exhibited $89 \%$ removal efficiency in comparison to its first usage, as shown in Figure 8b. SEM images of reused H50 are presented in Figure 8c, showing no structural damage on the fiber morphology. An investigation of the adsorption ability of HMDI/HPIM-FMs was performed by comparing dense (film) and fibrous membranes of $\mathrm{H} 50$. Note that the production of the film form of H50 was significantly more difficult by the solvent evaporation method. We were able to detach the membrane from the glass surface, but maintaining the membrane in a flat shape was not possible. The membrane was prone to roll by 


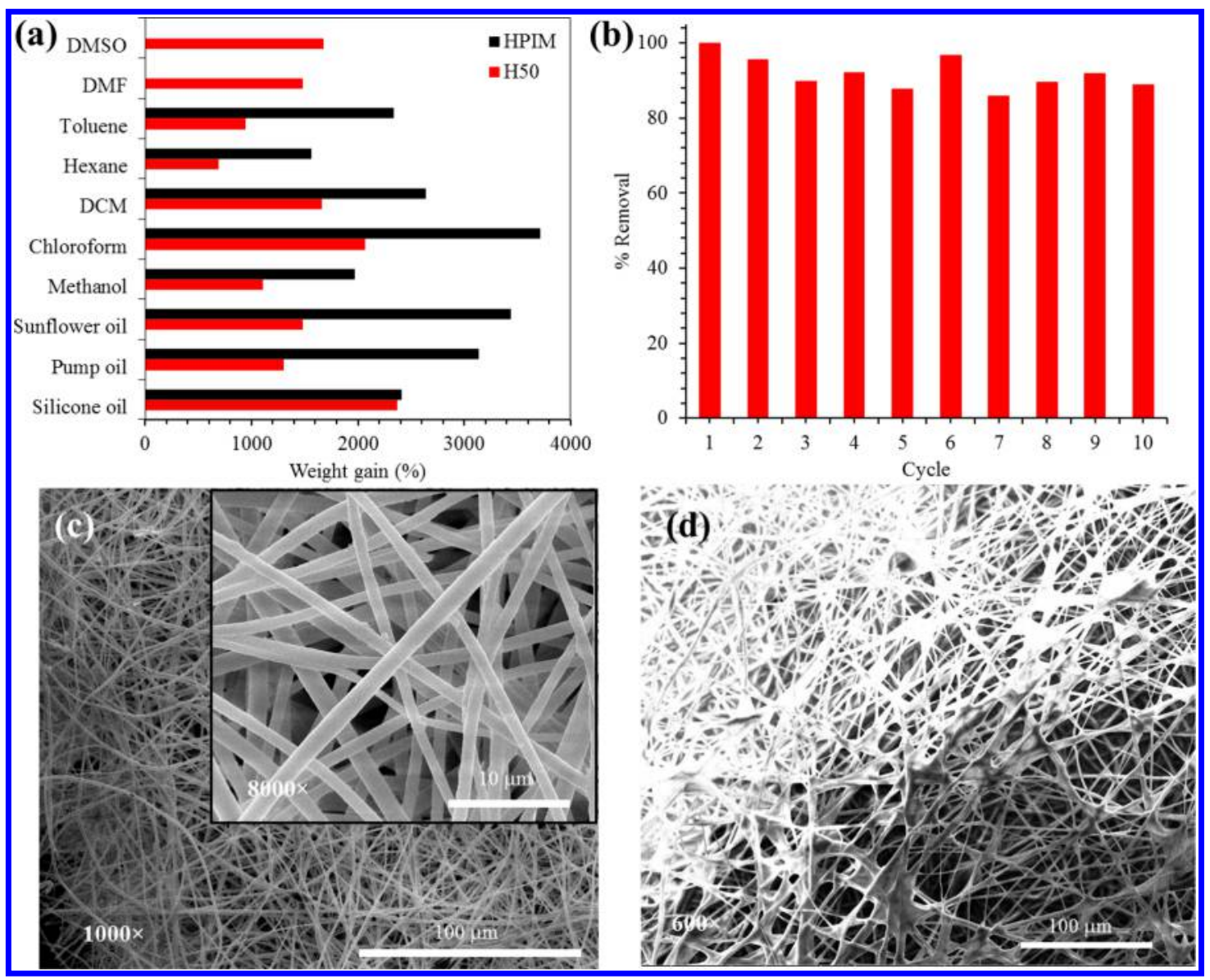

Figure 8. (a) Adsorption capacities of HPIM and H50 toward different organic liquids and oils, (b) \% removal of pump oil by H50 in 10 adsorption/ desorption cycles, (c) SEM images of H50 after 10 pump oil higher (inset) and lower magnification adsorptions, and (d) SEM image of an oiladsorbed H50 fibrous membrane.

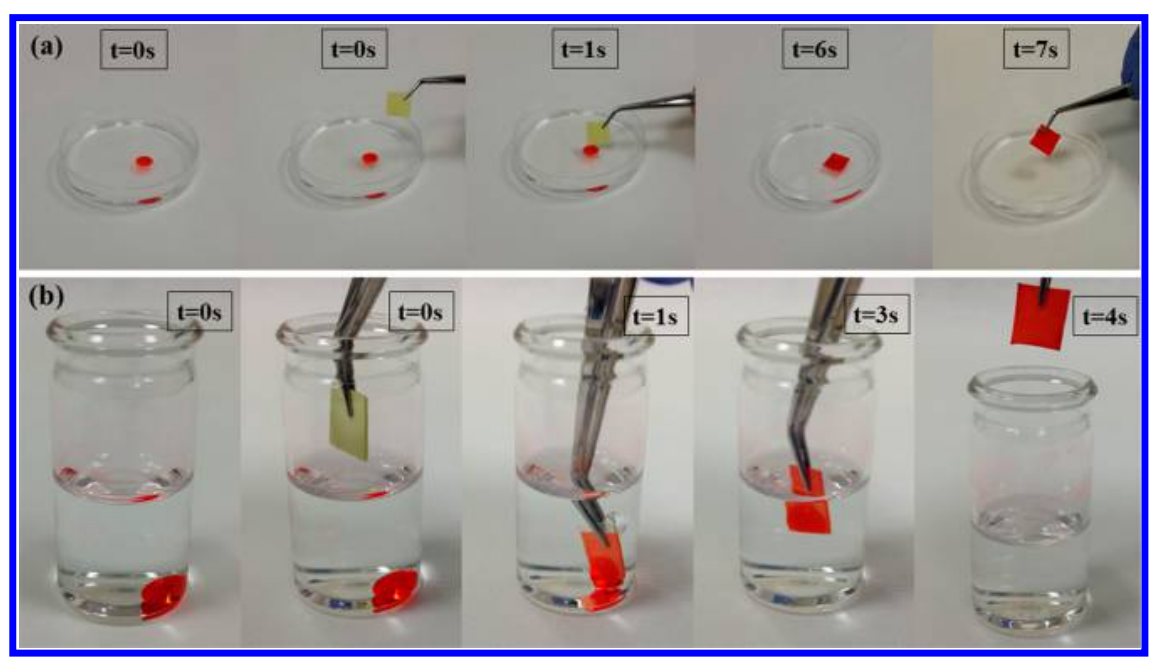

Figure 9. Digital images showing the adsorption performance of H50 on organic compounds upon removal of (a) pump oil (red) from the water surface and (b) $\mathrm{CHCl}_{3}$ (red) from the bottom of water as a function of time.

itself as the solvent evaporated (Figure S7). It is now wellknown that PIM-1 has high BET surface area ${ }^{54}\left(\sim 770 \mathrm{~m}^{2} \mathrm{~g}^{-1}\right)$, and it can adsorb organic molecules from its surroundings. Similarly, HPIM also has a relatively high surface area (Figure $\mathrm{S} 8)$ in powder form $\left(\sim 400 \mathrm{~m}^{2} \mathrm{~g}^{-1}\right)$, but it loses its surface area in the membrane form $\left(\sim 20 \mathrm{~m}^{2} \mathrm{~g}^{-1}\right) .^{43}$ The addition of HMDI cross-linking further reduces the surface area of the fibrous membrane (Figure S8). Owing to a reduction in the surface area, the adsorption performance of HMDI/HPIM-FMs can only be explained by the $3 \mathrm{D}$ structure of the fibrous membranes. Great hydrophobicity, along with a fibrous nature, enables HMDI/HPIM-FMs to have high adsorption capacity. Comparative pump oil adsorption of the dense and fibrous membranes of $\mathrm{H} 50$ has been studied to support this idea. While the dense form can only have $60 \%$ weight gain, which is due to the accumulation of oils on the film surface, the fibrous 
membrane can reach up to $1300 \%$ weight because of the fibrous nature. This further provides a slightly dried SEM image of H50 after oil adsorption in Figure 8d. As can be seen, oil can penetrate inside the fibrous membrane and remains there. In addition, the change in the dimensions of fibrous membranes is investigated using isopropyl alcohol. The samples with dimensions of $3 \times 3$ were employed for HPIM and H50. After an effective equilibrium was reached, both samples were swollen and increased in size. However, HPIM was not a handful material, and weight measurement was not successfully conducted, as experienced in the oil/water separation experiment (Figure S9). On the other hand, H50 maintained its membrane structure (Figure S9), and it had a significant weight gain of around $2200 \%$ and a $\sim 10 \%$ increase in its dimensions, as shown in Figure S10.

The oil adsorption capacity of HMDI/HPIM-FMs (H50) was found to be approximately between 13 and $25 \mathrm{mg} \mathrm{g}^{-1}$, depending on the type of the oil that was used in the experiment (derived from Figure 8a). Some examples of oil adsorbents and their adsorption capacities along with their structural forms are provided in Table S2. ${ }^{55-61}$ The adsorption capacity of $\mathrm{H} 50$ is not the highest data in the literature, but it is greater than those of many other oil adsorbents. In addition, the research related to electrospun PIMs is still in its early stages. It is highly possible that the capacity may be easily improved in the future by using different forms of PIM and cross-linker structure. Nevertheless, within the scope of this study, the reusability and durability of the HPIM fibrous membrane were improved by the introduced modification. The feasibility of HMDI/HPIM-FMs for practical applications was further demonstrated by using $\mathrm{H} 50$ to separate two organic compounds (pump oil and $\mathrm{CHCl}_{3}$ ) with different intensities from an aqueous system. As shown in Figure 9a, pump oil (colored by Sudan III) can be immediately and selectively adsorbed by a piece of $\mathrm{H} 50$ mat as a result of the superhydrophobic surface and 3D interconnected fibrous structure. The membrane was still floating on the water surface after adsorption because of the low density, which may help to remove oil easily from water. In another example, a piece of $\mathrm{H} 50$ mat was soaked in water to adsorb $\mathrm{CHCl}_{3}$ (colored by Sudan III), which was at the bottom of water (Figure 9b). The results clearly show that HMDI/HPIM-FMs could immediately separate organic compounds from aqueous systems regardless of their densities. The rapid separation can be seen in supporting video S3 (oil adsorption) and supporting video S4 ( $\mathrm{CHCl}_{3}$ adsorption). The reusability and adsorption/desorption performances of HPIM and H50 were also investigated in effective oil/water separation experiments several times, as presented in supporting video S5 (HPIM) and supporting video S6 (H50). While $\mathrm{H} 50$ can be used five times continuously in oil/water separation experiments without sustaining any damage to its structural stability, HPIM loses its membrane form after 2 cycles of separation. Thus, it is not suitable for practical oil/water separation.

\section{CONCLUSION}

HMDI/HPIM-FMs were successfully fabricated by an electrospinning technique prior to thermal treatment. In order to evaluate the effect of modification on the properties of electrospun HPIM-FM, the fiber morphology, mechanical strength, adsorption and separation performances, and thermal resistance were investigated. HMDI/HPIM-FMs were found to be insoluble in common organic solvents. In addition to insolubility, the materials are thermally and chemically stable up to $240{ }^{\circ} \mathrm{C}$. The mechanical properties of HPIM-FM were also improved by HMDI modification, in which HMDI/HPIM-FMs have shown higher Young's and storage moduli compared to pristine HPIM-FM. HMDI/HPIM-FMs have demonstrated superhydrophobicity with water contact angles of up to $159 \pm$ $7^{\circ}$. Therefore, they were successfully employed in adsorption and separation applications. Owing to the mechanical strength, insolubility, and superhydrophobicity, HMDI/HPIM-FMs exhibited notable adsorption and separation performances along with high reusability.

\section{ASSOCIATED CONTENT}

\section{Supporting Information}

The Supporting Information is available free of charge on the ACS Publications website at DOI: 10.1021/acsanm.8b00115.

Characterization of PIM-1 and HPIM, optimization of the membrane production, and organic and oil adsorption (PDF)

Supporting video S1 (HPIM flexibility) (AVI)

Supporting video S2 (H50 flexibility) (AVI)

Supporting video S3 (oil adsorption) (AVI)

Supporting video $\mathrm{S} 4\left(\mathrm{CHCl}_{3}\right.$ adsorption) (AVI)

Supporting video S5 (HPIM oil/water separation) (AVI)

Supporting video S6 (H50 oil/water separation) (AVI)

\section{AUTHOR INFORMATION}

\section{Corresponding Authors}

*E-mail: bekir.satilmis@ahievran.edu.tr (B.S.).

*E-mail: uyar@unam.bilkent.edu.tr (T.U.).

ORCID

Bekir Satilmis: 0000-0002-3704-8628

\section{Author Contributions}

The manuscript was written through contributions of all authors. All authors have given approval to the final version of the manuscript.

Notes

The authors declare no competing financial interest.

\section{ACKNOWLEDGMENTS}

The authors thank Dr. Amaresh C. Pradhan for his practical help with XPS analysis.

\section{REFERENCES}

(1) Motta, F. L.; Stoyanov, S. R.; Soares, J. B. P. Application of Solidifiers for Oil Spill Containment: A Review. Chemosphere 2018, 194, 837-846.

(2) Errington, I.; King, C. K.; Wilkins, D.; Spedding, T.; Hose, G. C. Ecosystem Effects and The Management of Petroleum-Contaminated Soils on Subantarctic Islands. Chemosphere 2018, 194, 200-210.

(3) Chen, P.-Y.; Tung, S.-H. One-Step Electrospinning To Produce Nonsolvent-Induced Macroporous Fibers with Ultrahigh Oil Adsorption Capability. Macromolecules 2017, 50, 2528-2534.

(4) Jiang, Z.; Tijing, L. D.; Amarjargal, A.; Park, C. H.; An, K.-J.; Shon, H. K.; Kim, C. S. Removal of Oil From Water Using Magnetic Bicomponent Composite Nanofibers Fabricated by Electrospinning. Composites, Part B 2015, 77, 311-318.

(5) Huang, M.; Si, Y.; Tang, X.; Zhu, Z.; Ding, B.; Liu, L.; Zheng, G.; Luo, W.; Yu, J. Gravity Driven Separation of Emulsified Oil-Water Mixtures Utilizing In Situ Polymerized Superhydrophobic and Superoleophilic Nanofibrous Membranes. I. Mater. Chem. A 2013, 1, 14071-14074. 
(6) Padaki, M.; Surya Murali, R.; Abdullah, M. S.; Misdan, N.; Moslehyani, A.; Kassim, M. A.; Hilal, N.; Ismail, A. F. Membrane Technology Enhancement In Oil-Water Separation. A Review. Desalination 2015, 357, 197-207.

(7) Fritt-Rasmussen, J.; Brandvik, P. J. Measuring Ignitability for In Situ Burning of Oil Spills Weathered Under Arctic Conditions: From Laboratory Studies to Large-Scale Field Experiments. Mar. Pollut. Bull. 2011, 62, 1780-1785.

(8) Castro, A.; Iglesias, G.; Carballo, R.; Fraguela, J. A. Floating Boom Performance Under Waves and Currents. I. Hazard. Mater. 2010, 174, 226-235.

(9) Prince, R. C.; McFarlin, K. M.; Butler, J. D.; Febbo, E. J.; Wang, F. C. Y.; Nedwed, T. J. The Primary Biodegradation of Dispersed Crude Oil In The Sea. Chemosphere 2013, 90, 521-526.

(10) Ge, J.; Zhao, H.-Y.; Zhu, H.-W.; Huang, J.; Shi, L.-A.; Yu, S.-H. Advanced Sorbents for Oil-Spill Cleanup: Recent Advances and Future Perspectives. Adv. Mater. 2016, 28, 10459-10490.

(11) Dong, Z.-Q.; Ma, X.-h.; Xu, Z.-L.; You, W.-T.; Li, F.-b. Superhydrophobic PVDF-PTFE Electrospun Nanofibrous Membranes for Desalination by Vacuum Membrane Distillation. Desalination 2014, 347, 175-183.

(12) Lin, J.; Cai, Y.; Wang, X.; Ding, B.; Yu, J.; Wang, M. Fabrication of Biomimetic Superhydrophobic Surfaces Inspired by Lotus Leaf and Silver Ragwort Leaf. Nanoscale 2011, 3, 1258-1262.

(13) Koo, S. H.; Lee, S. G.; Bong, H.; Kwark, Y.-J.; Cho, K.; Lim, H. S.; Cho, J. H. Robust Multifunctional Superhydrophobic OrganicInorganic Hybrid Macroporous Coatings and Films. Polvmer 2014, 55, 2661-2666.

(14) Li, J.; Fu, J.; Cong, Y.; Wu, Y.; Xue, L.; Han, Y. Macroporous Fluoropolymeric Films Templated by Silica Colloidal Assembly: A Possible Route to Super-Hydrophobic Surfaces. Appl. Surf. Sci. 2006, 252, 2229-2234.

(15) Ogawa, T.; Ding, B.; Sone, Y.; Shiratori, S. Super-Hydrophobic Surfaces of Layer-by-Layer Structured Film-Coated Electrospun Nanofibrous Membranes. Nanotechnology 2007, 18, 165607.

(16) $\mathrm{Wu}, \mathrm{X}$.; Shi, G. Production and Characterization of Stable Superhydrophobic Surfaces Based on Copper Hydroxide Nanoneedles Mimicking the Legs of Water Striders. I. Phvs. Chem. B 2006, 110, 11247-11252.

(17) Ueda, E.; Levkin, P. A. Emerging Applications of Superhydrophilic-Superhydrophobic Micropatterns. Adv. Mater. 2013, 25, 1234-1247.

(18) Nuraje, N.; Khan, W. S.; Lei, Y.; Ceylan, M.; Asmatulu, R. Superhydrophobic Electrospun Nanofibers. I. Mater. Chem. A 2013, 1 , 1929-1946.

(19) Arslan, O.; Aytac, Z.; Uyar, T. Superhydrophobic, Hybrid, Electrospun Cellulose Acetate Nanofibrous Mats for Oil/Water Separation by Tailored Surface Modification. ACS Appl. Mater. Interfaces 2016, 8, 19747-19754.

(20) Lim, J.-M.; Yi, G.-R.; Moon, J. H.; Heo, C.-J.; Yang, S.-M. Superhydrophobic Films of Electrospun Fibers with Multiple-Scale Surface Morphology. Langmuir 2007, 23, 7981-7989.

(21) Wang, X.; Yu, J.; Sun, G.; Ding, B. Electrospun Nanofibrous Materials: A Versatile Medium for Effective Oil/Water Separation. Mater. Todav 2016, 19, 403-414.

(22) Tai, M. H.; Gao, P.; Tan, B. Y. L.; Sun, D. D.; Leckie, J. O. Highly Efficient and Flexible Electrospun Carbon-Silica Nanofibrous Membrane for Ultrafast Gravity-Driven Oil-Water Separation. ACS Appl. Mater. Interfaces 2014, 6, 9393-9401.

(23) Carta, M.; Msayib, K. J.; McKeown, N. B. Novel Polymers of Intrinsic Microporosity (PIMs) Derived from 1,1-spiro-bis(1,2,3,4Tetrahydronaphthalene)-Based Monomers. Tetrahedron Lett. 2009, 50, 5954-5957.

(24) Budd, P. M.; McKeown, N. B. Highly Permeable Polymers for Gas Separation Membranes. Polvm. Chem. 2010, 1, 63-68.

(25) Thomas, J. C.; Trend, J. E.; Rakow, N. A.; Wendland, M. S.; Poirier, R. J.; Paolucci, D. M. Optical Sensor for Diverse Organic Vapors at ppm Concentration Ranges. Sensors 2011, 11, 3267.
(26) Wang, Y.; McKeown, N. B.; Msayib, K. J.; Turnbull, G. A.; Samuel, I. D. W. Laser Chemosensor with Rapid Responsivity and Inherent Memory Based on a Polymer of Intrinsic Microporosity. Sensors 2011, 11, 2478-2487.

(27) Ramimoghadam, D.; Gray, E. M.; Webb, C. J. Review of Polymers of Intrinsic Microporosity for Hydrogen Storage Applications. Int. I. Hvdrogen Energy 2016, 41, 16944-16965.

(28) Mackintosh, H. J.; Budd, P. M.; McKeown, N. B. Catalysis by Microporous Phthalocyanine and Porphyrin Network Polymers. I. Mater. Chem. 2008, 18, 573-578.

(29) McKeown, N. B.; Budd, P. M. Polymers of Intrinsic Microporosity (PIMs): Organic Materials for Membrane Separations, Heterogeneous Catalysis and Hydrogen Storage. Chem. Soc. Rev. 2006, $35,675-683$

(30) Budd, P. M.; Ghanem, B. S.; Makhseed, S.; McKeown, N. B.; Msayib, K. J.; Tattershall, C. E. Polymers of Intrinsic Microporosity (PIMs): Robust, Solution-Processable, Organic Nanoporous Materials. Chem. Commun. 2004, 230-231.

(31) Zhang, C.; Li, P.; Cao, B. Electrospun Polymer of Intrinsic Microporosity Fibers and Their Use In The Adsorption of Contaminants From A Nonaqueous System. J. Appl. Polym. Sci. 2016, 133, 43475.

(32) Satilmis, B.; Budd, P. M. Selective Dye Adsorption by Chemically-Modified and Thermally-Treated Polymers of Intrinsic Microporosity. I. Colloid Interface Sci. 2017, 492, 81-91.

(33) Bonso, J. S.; Kalaw, G. D.; Ferraris, J. P. High Surface Area Carbon Nanofibers Derived from Electrospun PIM-1 for Energy Storage Applications. I. Mater. Chem. A 2014, 2, 418-424.

(34) Zhang, C.; Li, P.; Cao, B. Electrospun Microfibrous Membranes Based on PIM-1/POSS with High Oil Wettability for Separation of Oil-Water Mixtures and Cleanup of Oil Soluble Contaminants. Ind. Eng. Chem. Res. 2015, 54, 8772-8781.

(35) Satilmis, B.; Budd, P. M. Base-Catalysed Hydrolysis of PIM-1: Amide Versus Carboxylate Formation. RSC Adv. 2014, 4, 5218952198.

(36) Du, N.; Robertson, G. P.; Song, J.; Pinnau, I.; Guiver, M. D. High-Performance Carboxylated Polymers of Intrinsic Microporosity (PIMs) with Tunable Gas Transport Properties. Macromolecules 2009, 42, 6038-6043.

(37) Mason, C. R.; Maynard-Atem, L.; Al-Harbi, N. M.; Budd, P. M.; Bernardo, P.; Bazzarelli, F.; Clarizia, G.; Jansen, J. C. Polymer of Intrinsic Microporosity Incorporating Thioamide Functionality: Preparation and Gas Transport Properties. Macromolecules 2011, 44, 6471-6479.

(38) Mason, C. R.; Maynard-Atem, L.; Heard, K. W. J.; Satilmis, B.; Budd, P. M.; Friess, K.; Lanč, M.; Bernardo, P.; Clarizia, G.; Jansen, J. C. Enhancement of $\mathrm{CO} 2$ Affinity in a Polymer of Intrinsic Microporosity by Amine Modification. Macromolecules 2014, 47, 1021-1029.

(39) Patel, H. A.; Yavuz, C. T. Noninvasive Functionalization of Polymers of Intrinsic Microporosity for Enhanced CO2 Capture. Chem. Commun. 2012, 48, 9989-9991.

(40) Satilmis, B.; Alnajrani, M. N.; Budd, P. M. Hydroxyalkylaminoalkylamide PIMs: Selective Adsorption by Ethanolamine- and Diethanolamine-Modified PIM-1. Macromolecules 2015, 48, 56635669.

(41) Du, N.; Park, H. B.; Robertson, G. P.; Dal-Cin, M. M.; Visser, T.; Scoles, L.; Guiver, M. D. Polymer Nanosieve Membranes for CO2Capture Applications. Nat. Mater. 2011, 10, 372-375.

(42) Zhang, C.; Li, P.; Huang, W.; Cao, B. Selective Adsorption and Separation of Organic Dyes In Aqueous Solutions by Hydrolyzed PIM-1 Microfibers. Chem. Eno. Res. Des. 2016, 109, 76-85.

(43) Satilmis, B.; Budd, P. M.; Uyar, T. Systematic Hydrolysis of PIM-1 and Electrospinning of Hydrolyzed PIM-1 Ultrafine Fibers for An Efficient Removal of Dye From Water. React. Funct. Polvm. 2017, 121, 67-75.

(44) Fritsch, D.; Merten, P.; Heinrich, K.; Lazar, M.; Priske, M. High Performance Organic Solvent Nanofiltration Membranes: Development and Thorough Testing of Thin Film Composite Membranes 
Made of Polymers of Intrinsic Microporosity (PIMs). L. Membr. Sci.

2012, 401-402, 222-231.

(45) Rong, Y.; Kolodziej, A.; Madrid, E.; Carta, M.; Malpass-Evans, R.; McKeown, N. B.; Marken, F. Polymers of Intrinsic Microporosity In Electrochemistry: Anion Uptake and Transport Effects In Thin Film Electrodes and In Free-Standing Ionic Diode Membranes. I. Electroanal. Chem. 2016, 779, 241-249.

(46) Zhou, Y.; Sheng, D.; Liu, X.; Lin, C.; Ji, F.; Dong, L.; Xu, S.; Yang, Y. Synthesis and Properties of Crosslinking Halloysite Nanotubes/Polyurethane-Based Solid-Solid Phase Change Materials. Sol. Energy Mater. Sol. Cells 2018, 174, 84-93.

(47) Fernandez d'Arlas, B.; Rueda, L.; Stefani, P. M.; de la Caba, K.; Mondragon, I.; Eceiza, A. Kinetic and Thermodynamic Studies of The Formation of A Polyurethane Based on 1,6-Hexamethylene Diisocyanate and Poly(Carbonate-Co-Ester)Diol. Thermochim. Acta 2007, 459, 94-103.

(48) Fernández-d'Arlas, B.; Alonso-Varona, A.; Palomares, T.; Corcuera, M. A.; Eceiza, A. Studies on The Morphology, Properties and Biocompatibility of Aliphatic Diisocyanate-Polycarbonate Polyurethanes. Polvm. Degrad. Stab. 2015, 122, 153-160.

(49) Zha, F.; Li, S.; Chang, Y. Preparation and Adsorption Property of Chitosan Beads Bearing $\beta$-Cyclodextrin Cross-Linked by 1,6Hexamethylene Diisocyanate. Carbohvdr. Polvm. 2008, 72, 456-461.

(50) Ranjbar, Z.; Montazeri, S.; Nayini, M. M. R.; Jannesari, A. Synthesis and Characterization of Diethylene Glycol Monobutyl Ether-Blocked Diisocyanate Crosslinkers. Prog. Org. Coat. 2010, 69, $426-431$.

(51) Wang, W.; Jin, X.; Zhu, Y.; Zhu, C.; Yang, J.; Wang, H.; Lin, T. Effect of Vapor-Phase Glutaraldehyde Crosslinking on Electrospun Starch Fibers. Carbohvdr. Polvm. 2016, 140, 356-361.

(52) Ma, M.; Mao, Y.; Gupta, M.; Gleason, K. K.; Rutledge, G. C. Superhydrophobic Fabrics Produced by Electrospinning and Chemical Vapor Deposition. Macromolecules 2005, 38, 9742-9748.

(53) Quéré, D. Rough Ideas on Wetting. Phys. A 2002, 313, 32-46.

(54) Budd, P. M.; McKeown, N. B.; Fritsch, D. Free Volume and Intrinsic Microporosity In Polymers. L. Mater. Chem. 2005, 15, 19771986.

(55) Choi, H. M. Needlepunched Cotton Nonwovens and Other Natural Fibers as Oil Cleanup Sorbents. L.Environ. Sci. Health, Part A: Environ. Sci. Eng. Toxic Hazard. Subst. Control 1996, 31, 1441-1457.

(56) Lin, C.; Hong, Y.-J.; Hu, A. H. Using A Composite Material Containing Waste Tire Powder and Polypropylene Fiber Cut End To Recover Spilled Oil. Waste Manage. 2010, 30, 263-267.

(57) Pan, Y.; Shi, K.; Peng, C.; Wang, W.; Liu, Z.; Ji, X. Evaluation of Hydrophobic Polyvinyl-Alcohol Formaldehyde Sponges As Absorbents for Oil Spill. ACS Appl. Mater. Interfaces 2014, 6, 8651-8659.

(58) Liao, Q.; Su, X.; Zhu, W.; Hua, W.; Qian, Z.; Liu, L.; Yao, J. Flexible and Durable Cellulose Aerogels for Highly Effective Oil/ Water separation. RSC Adv. 2016, 6, 63773-63781.

(59) Wu, J.; Wang, N.; Wang, L.; Dong, H.; Zhao, Y.; Jiang, L. Electrospun Porous Structure Fibrous Film with High Oil Adsorption Capacity. ACS Appl. Mater. Interfaces 2012, 4, 3207-3212.

(60) Tian, L.; Zhang, C.; He, X.; Guo, Y.; Qiao, M.; Gu, J.; Zhang, Q. Novel Reusable Porous Polyimide Fibers for Hot-Oil Adsorption. I. Hazard. Mater. 2017, 340, 67-76.

(61) Deschamps, G.; Caruel, H.; Borredon, M.-E.; Bonnin, C.; Vignoles, C. Oil Removal from Water by Selective Sorption on Hydrophobic Cotton Fibers. 1. Study of Sorption Properties and Comparison with Other Cotton Fiber-Based Sorbents. Environ. Sci. Technol. 2003, 37, 1013-1015. 